\title{
POWER DAN AKTIVISME TRANSNASIONAL DALAM STUDI HUBUNGAN INTERNASIONAL
}

\author{
Yusnarida Eka Nizmi \\ Dosen FISIP-HI Universitas Riau \\ eka_nizmi@yahoo.com
}

\begin{abstract}
ABSTRAK
Tulisan ini mencoba untuk berpartisipasi menambah literatur mengenai kajian gerakangerakan sosial dan kelompok-kelompok swadaya masyarakat yang beroperasi melintasi batas negara. Tujuan dari tulisan ini adalah untuk memperlihatkan adanya kesenjangan yang signifikan dalam kontekstualisasi aktivisme transnasional antara negara dan organisasiorganisasi masyarakat termasuk juga NGO. Tulisan ini juga akan mencoba unutk memberikan wacana baru mengenai persoalan aktivisme politik dalam konteks transnasional. Proses globalisasi tidak hanya murni melibatkan aspek ekonomi dan elit-elit politik. Interaksi lintas batas antar aktor-aktor masyarakat sipil (globalization from below) adalah salah satu fenomena dalam dunia politik kontemporer untuk menerima tingginya perhatian media dan dunia akademik. Ketika NGO dan gerakan sosial tidak hanya fokus pada wilayah domestik atau lokal namun juga bertindak melewati batas-batas negara, disitulah aktivitas transnasional meningkat. Aktivitas politik transnasional menantang pemahaman konvensional mengenai civil society dan gerakan sosial termasuk juga hubungan internasional.
\end{abstract}

Kata kunci : gerakan sosial, aktivisme transnasional, globalisasi, power, hubungan internasional

\begin{abstract}
This paper attempts to participate in the literature on the study of social movements and selfhelp groups operating across national borders. The purpose of this paper is to show a significant gap in the contextualisation of transnational activism between state and community organizations as well as NGOs. This paper will also try to give a new discourse on the issue of political activism in a transnational context. The process of globalization is not only purely economic and political elites. Cross-border interaction among civil society actors (globalization from below) is one of the phenomena in contemporary politics to receive high media and academic attention. When NGOs and social movements not only focus on domestic or local areas but also act across national borders, that is where transnational activity increases. Transnational political activity challenges conventional understanding of civil society and social movements as well as international relations.
\end{abstract}

Key words : social movements, transnational activism, globalization, power, international relations. 


\section{Pendahuluan}

Tulisan ini hadir karena dipengaruhi beberapa pertanyaan seputar transnasionalisme yang antara lain mempertanyakan aktor yang bagimana yang menjadi bagian dalam aktivisme transnasional? Siapa saja yang menjadi relasinya/targetnya? Bagaimana power negara dapat hadir dalam aktivisme transnasional? Bagaimana memahami power dalam jaringan aktivis transnasional? Menjawab pertanyaan-pertanyaan ini, akan dimulai dengan memaparkan mengenai konsep "aktivisme" dalam konteks transnasional. Tulisan ini pun akan mengklarifikasi beragam tipe mengenai aktor yang terlibat dalam aktivisme transnasional. Elaborasi mengenai perspektif power dalam lingkup aktivisme transnasional juga menjadi bagian bahasan yang akan membantu untuk memahami aktivisme transnasional.

Aktivisme transnasional secara sejarah bukanlah sebuah fenomena baru. Aktor-aktor masyarakat sipil konsen dalam isu yang melibatkan aktivitas lintas negara setidaknya sudah ada sejak abad kesembilan belas (Keck and Sikkink 1998). Pola aktivisme internasional saat ini telah mengalami perubahan. kecenderungan ideologi jaringan aktivis transnasional kontemporer termasuk gerakan radikal anti sistem sayap kiri, gerakan xenophobic dan fasis pada ekstrim sayap kanan, jaringan aktivis agama, dan isu-isu lain yang NGO secara spesifik terlibat dengan batasanbatasan sistem serta sering terlibat interaksi dan menjalin kerjasama dengan negara dan institusi-institusi internasional. Daripada memfokuskan secara eksklusif pada satu tipe kelompok transnasional (seperti jaringan advokasi transnasional, gerakan sosial transnasional, NGOs internasional, dan sebagainya), sebagaimana riset-riset terdahulu, tulisan ini akan memfokuskan pada aktivisme transnasional, termasuk beragam jenis aktor.

Aktivisme dalam aktivitas politik adalah : (1) didasarkan pada konflik kepentingan dan keberlangsungan negara; (2) melawan atau mendukung struktur power tertentu; (3) melibatkan aktor-aktor non negara; dan (4) aktif/terlibat diluar arena politik formal. Kriteria-kriteria ini membutuhkan beberapa elaborbagian dari eksekutif/bagian dari pemerintah parlementer (Keck and Sikking 1998: 9). Konsep jaringan yang dipakai disini mirip dengan analisa "network society" yang diungkap oleh Manuel Castells (1996). Jaringan dianggap sebagai sebuah bentuk baru sosial yang didasarkan pada tipe pertukaran- terutama pada informasi-antara para aktor yang berlokasi tidak di tempat/ruang/wilayah yang sama. Jaringan ini mengatur pertukaran-pertukaran informasi yang berhubungan dengan ekonomi, politik atau sosial yang relevan dari aktor-aktor tertentu didasarkan pada keterlibatan mereka dalam sebuah jaringan yang kuat.

Jaringan advokasi transnasional dicirikan oleh kerja advokasi mereka. Advokasi secara umum dipahami sebagai sebuah tindakan untuk mempengaruhi kebijakan. Jordan and van Tujil (2000:2052) menjabarkan defenisi yang lebih spesifik mengenai advokasi NGOs sebagai sebuah tindakan mengatur strategi penggunaan informasi untuk menyeimbangkan hubungan power yang tidak seimbang. Meskipun fokus pada strategi penggunaan informasi itu penting, defenisi ini speertinya menyamakan tujuan dan nilai-nilai yang diperjuangkan oleh semua aktivis NGOs. Padahal sudah disebutkan bahwa tidak semua NGOs terlibat dalam kerja advokasi yang ditujukan untuk demokratisasi. Advokasi NGOs mungkin bisa 
merangkum keseluruhan spektrum tujuan dari demokrasi sampai anti demokrasi dan kita juga tidak bisa mengasumsikan seluruh agenda NGOs pro demokrasi adalah sama. Termasuk juga menurut Jordan van Tuijl (2000: 2053) bahwa kita tidak boleh berasumsi bahwa semua NGOs menentang status quo. Sebagai tambahan dalam pemahaman advokasi, para aktivis transnasional bisa juga terlibat dalam mengawasi aktivis lainnya (misal terkait dengan hak asasi manusia) dan dalam memberikan layanan jasa (Florini 2000a: 213).

Peran NGOs cenderung tinggi untuk diuji. Bank Dunia dan banyak pemerintah mempromosikan peran NGOs sebagai bagian dari agenda neo-liberal untuk membatasi peran negara. Sebaliknya, banyak NGOs justu lebih tertarik dalam advokasi, menargetkan terjadinya hubungan baik dengan pemerintah dan institusiinstitusi internasional (Jordan and van Tuijl 2000: 2052). Fokus tulisan dalam aktivisme adalah untuk menjabarkan advokasi dan mengawasi beragam aktivitasbukan pada pemberian jasa meskipun diketahui bahwa beberapa NGOs ada intens terikat dalam advokasi dan pemberian layanan jasa.

Strategi penggunaan informasi, sepertinya menjadi kunci dalam aktivisme transnasional. Perkembangan komunikasi baru dan teknologi informasi diformat ulang, dengan menambahkan aktivitas seperti "e-mobilisasi" dan "cyber-activism" yang dianalisa oleh Lain. Sebagai jaringan komunikasi yang baru, hal ini dianggap sebagai bentuk " ruang transnasional publik" (Guidry and Zald 200b), yang berhubungan dengan masyarakat transnasional (atau global), sebuah fenomena yang mendapat banyak perhatian selama beberapa tahun terakhir ini.

Pembahasan mengenai seberapa besar otonomi civil society ketika berhubungan dengan pemerintah masih diperdebatkan dalam teori politik, dan pertanyaan yang sama juga muncul terkait dengan transnasional civil society. Kita sepakat dengan Sharp et al. (2000:10-11) bahwa "tidak ada ruang otonomi yang benar-benar sempurna". Demikian juga tidak ada civil society (transnasional maupun domestik) akan benar-benar otonomi bebas dari pengaruh power negara. Eksistensi masyarakat sipil transnasional (atau global) juga memunculkan pertanyaan mengenai warganegara transnasional atau global (Delanty 2000). Jika kepemilikian status warganegara dianggap sebagai sebuah hak, dan menjadi elemen untuk berhubungan dengan sebuah negara, maka minimnya keberadaan pemerintah global membuat konsep warganegara global menjadi sesuatu yang tidak mungkin. Namun, jika status kewarganegaraan dianggap sebagai partisipasi, maka terbuka ruang untuk mewujudkan status warganegara global (Gaventa 2001: 227-8). Banyak pertanyaan mengenai power dan aktivisme transnasional masih belum mendapatkan jawaban yang disepakati semua pihak dalam literatur-literatur mengenai aktivisme transnasional, tulisan ini mencoba menjawab beragam pertanyaan tersebut.

\section{Pembahasan}

\section{Aktivisme Transnasional Dalam Ragam Pendekatan}

Kajian aktivisme transnasional merupakan studi yang penting secara general karena melibatkan beragam disiplin ilmu. Pertama, studi hubungan internasional (HI), yang menyajikan paradigma negara sebagai aktor utama dalam sistem politik internasional yang anarki, dan kehadiran aktor-aktor non negara dalam politik 
internasional. Risse Kappen (1995), memaparkan tulisan Keohane dan Nye yang ditulis pada tahun 1970an, cukup membantu untuk memahami perspektif ini. Keck and Sikkink (1998) juga berpartisipasi untuk menjelaskan kajian aktivisme transnasional, yang juga diikuiti oleh yang lain (e.g. Risse, Ropp and Sikkink 1999; Scholte 1999; O’ Brien et al. 2000; Khagram, Riker and Sikkink 2002b).

Kedua, studi aktivisme transnasional dari perspektif Ekonomi Politik Internasional (EPI) yang memfokuskan pada issu power dan otoritas dalam sistem internasional (Higgot et al. 2000) serta kecenderungan aktivisme transnasional sebagai resistensi terhadap globalisasi neo-liberal (Mittelman 1999; Gills 2000).

Ketiga, tulisan dari perspektif yang berbeda, pakar sosiologi dan politik yang tertarik mengulas gerakan sosial yang berkembang menjadi gerakan transnasional atau meluas pada level global (Markoff 1996; Smith et al. 1997; Smith and Johnston 2002: Rucht 1999; Rucht 2001; Tarrow 1998; 2001; 2002; della Porta et al. 1999; Cohen and Rai 2000; Guidry, Kennedy and Zald 2000b; Hamel et al. 2001).

Keempat, politik dan studi pembangunan juga termasuk bagian dalam bahasan studi aktivitas non govermental organization (NGO), yang jarang masuk dalam literatur gerakan sosial secara eksplisit (e.g. Princen and Finger 1994; Hulme and Edwards 1997; Boli and Thomas 1999; Jordan and van Tuijl 2000; Uvin 2000). Kategori riset ini didasarkan pada studi empiris NGO dalam berbagai isu. Tema ini juga menjadi karakter publikasi mengenai transnasional atau global civil society (Florini 2000b; Warkentin 2001) and 'global citizen action' (Edwards and Gaventa 2001). 'Global Civil Society Yearbook' (Anheier et al. 2001) juga memaparkan isu ini untuk memetakan aktivitas-aktivitas "global civil society".

Kelima, beberapa studi mikro antropologi dari aktivisme transnasional menawarkan pandangan yang menarik dari level masyarakat bawah (Braman and Sreberny-Mohammadi 1996; Smith and Guranizo 1998; Riles 2000; Fortun 2001; Burawoy et al. 2000). Keenam, teori politik, memiliki sejumlah teori yang berusaha untuk mengusung teori bagi aktivisme transnasional yang tidak tersedia dalam studistudi lain. Teori-teori transnasional/global/ international civil society dipakai baik oleh versi liberal (Kaldor 1999) maupun neo- Marxist (Colas 2002). Studi ini juga berhubungan dengan "demokrasi kosmopolitan" (Held 1995) dan transnasional/masyarakat global (Delanty 2000). Ketujuh, riset aktivisme transnasional dari perspektif hukum internasional (Cullen and Morrow 2001).

Terakhir, ada banyak teks tertulis dari perspektif aktivis yang berkontribusi untuk memahami perkembangan gerakan sosial global melawan "globalization from above" (Brecher, Costello and Smith 2002). Meskipun ada beberapa riset yang tumpang tindih mengenai aktivisme transnasional (khususnya antara studi HI mengenai aktor non negara dan teori gerakan sosial, namun dapat dikatakan bahwa aktivisme transnasional sudah menjadi riset studi yang multidisiplin. Secara keseluruhan tulisan ini mencoba untuk mengintegrasikan beragam perspektif tersebut. Namun harus disadari bahwa tidak satupun dari studi-studi tersebut yang menawarkan kajian aktivisme transnasional yang menjabarkan sturktur power secara luas mengenai mikro politik dari power komunikasi.

Dengan mengabaikan pembahasan pentingnya power negara struktur power nasional dan internasional, banyak peneliti yang terlalu optimis mengenai apa yang 
bisa diraih oleh para aktivis transnasional. Sebagai tambahan, banyak studi yang justru cenderung berkutat di dinamika "negara versus civil society" dalam sebuah dikotomi, prilaku oposisi, wilayah kajian yang dalam tulisan ini justru dianggap sebagai pelengkap. Tulisan ini justru sepakat akan pentingnya sinergi anatara negara dan masyarakat sipil. Riset-riset terdahulu juga minim elaborasi analisis mengenai masalah demokrasi, baik mengenai hubungan antara peluang politik bagi aktivisme transnasional dan aktivis yang menjadi bagian dari perjuangan demokrasi, termasuk juga minim bahasan mengenai masalah demokrasi dan ketidaksetaraan dalam jaringan transnasional dan prospek bagi demokrasi transnasional. Cara terbaik untuk melakukan riset mengenai aktivisme transnasional adalah dengan melakukan analisis yang komprehensif mengenai aktivisme transnasional dalam konteks power dan hubungannya dengan masalah-masalah demokrasi. Namun terlebih dahulu, yang utama yang harus dilakukan adalah mendefenisikan konsep "aktivisme transnasional"- dengan harapan mendapatkan poin kunci untuk melakukan riset mengenai gerakan sosial, NGOs, dan aktor-aktor civil society yang beroperasi melintasi batas negara.

\section{Dimensi Power dalam Aktivisme Transnasional}

Power adalah sebuah konsep yang multidimensi dan sangat kompleks. Menurut Lukas (1986), sudah menjadi kebiasaan untuk membedakan antara (1) pendekatan konvensional power sebagai dominasi dan kontrol (2) power sebagai "non- decision-making (Bachrach and Baratz), dan (3) hegemoni ideologi dan power ide (Lukes). Elaborasi kemudian dilakukan oleh pemikiran Foucauldian, power bukan sebagai milik dari aktor tertentu namun power ada di seluruh aktivitas sosial dan memiliki beragam elemen (Sharp et al. 2000). Menurut Sharp et al. (2000), dialektikal power tidak hanya sebagai unsur dalam mendominasi namun juga dalam bentuk yang lebih positif, atau "power untuk bertahan" yang berhubungan dengan "komunikatif" atau "diskursus power yang dijalankan oleh jaringan aktivis transnasional dengan menggunakan strategi informasi dalam prilaku yang persuasif. Kita juga perlu untuk membuat elemen-elemen power untuk memudahkan pemahaman mengenai power (Sharp et al.2000: 1) dan untuk mengetahui ada ambiguitas dan kontradiksi dari power dan resistensi (Guidry, Kennedy and Zald 2000a: 17).

Sebagaimana yang diungkapkan oleh Massey (2000: 280), bahwa power ada dimana-mana dan sudah seharusnya mengabaikan struktur ketidakseimbangan power. Isu power tidak terlalu digali secara serius dalam kajian aktivisme transnasional. Cara terbaik untuk mengisi kekosongan ini adalah mengkombinasikan (1) melalui investigasi bagaimana struktur power dari sistem negara dan ekonomi kapitalis membentuk aktivisme transnasional dan (2) menganalisis diskursus power dan elemen-elemen power dalam level mikro. Namun sebelumnya, harus dipaparkan terlebih dahulu mengenai pendekatan konvensional makro level dari power, memaparkan struktur power dari negara-negara dan kapitalisme global dan resistensi power (baik yang potensial dan/atau nyata) dalam konteks ini, dilakukan oleh aktivis transnasional. 


\section{Power Negara dan Aktivisme}

Dibutuhkan pemahaman yang lebih komprehensif mengenai perspektif power dalam menganalisa bagaimana power negara mempengaruhi kondisi aktivisme transnasional dari institusi-institusi internasional. Banyak yang meyakini bahwa power negara tidak terlalu diperhitungkan dalam banyak riset mengenai aktivisme transnasional. Tulisan ini menganalisa bahwa aktivis transnasional terkait dengan negara dan institusi-institusi internasional, sesuatu yang jarang diulas dalam riset-riset sebelumnya (cf. Tarrow 2001). Dalam banyak literatur globalisasi, mengklaim bahwa negara telah kehilangan kedaulatan, Jean Grugel mengungkapkan bahwa perlunya mengkaji mengenai power negara secara serius dengan melakukan diskusi hubungan power antara negara dan masyarakat sipil (Grugel 1999: 1).

Lin's menunjukkan bahwa adanya ketidakseimbangan power secara spesifik antar negara dalam arena aktivisme transnasional. Aktivis transnasional Taiwan sangat dibatasi oleh masalah status diplomatik Taiwan. Aktivis dari Taiwan, misalnya tidak bisa menghadiri konferensi-konferensi yang diselenggarakan oleh PBB karena negara Taiwan tidak diterima sebagai anggota UN. Tidak diakuinya Taiwan sebagai sebuah negara dalam sistem internasional memberi persoalan tersendiri bagi aktivis-aktivis internasional yang berbasis di Taiwan (Chen Jie 2001). Meskipun ini merupakan kasus yang unik, perlu digarisbawahi bahwa negara tidak hanya membentuk pola aktivisme transnasional, namun juga mengindikasikan bahwa secara diplomatik pengakuan sebagai negara berdaulat memberi pengaruh bagi gerakan-gerakan aktivisme transnasional. Kita sepakat dengan literatur-literatur globalisasi yang menyatakan bahwa proses globalisasi memang telah merubah namun tidak langsung melemahkan power negara (e.g. Higgott, Underhill and Bieler 2000). ini berhubungan dengan observasi Colas yang mengungkapkan bahwa struktur dari sistem internasional masih memberi ruang pada gerakan-gerakan sosial untuk memasukkan berbagai tujuan agenda sosial politik mereka melalui organorgan yang berbeda dari negara yang berdaulat (Colas 2002: 79). Dapat dikatakan bahwa gerakan-gerakan sosial pada level internasional memang menguat sebagaimana juga kedaulatan negara (Colas 2002: 80). Pada level global, ini berarti bahwa negara masih dominan memegang posisi power (O'Brien et al. 2000: 224), sementara aktivis-aktivis internasional belum mampu secara signifikan mempengaruhi kebijakan dari insitusi-institusi ekonomi multilateral.

Penting untuk diketahui bahwa baik negara maupun masyarakat sipil samasama eksis dan berkembang dalam konteks sejarah kapitalisme (Comor 2001: 400). Gorg and Hirsch (1998: 586) mencatat adanya kontradiksi antara regulasi negara dari masyarakat kapitalis dan formasi demokrasinya, dimana power dari negara (sebagaimana yang dipahami memiliki kompetensi otonom dalam proses pembuatan keputusan dan implementasinya) secara tipikal bergantung pada hubungan dengan kelas-kelas tertentu secara domestik dan struktur internasional. Poin yang ingin ditunjukkan disini adalah bahwa kontradiksi antara negara dan pasar tidak begitu ekstrim sebagaimana yang dipikirkan. Pasar dan negara/demokrasi tidak terlalu berbenturan satu sama lain, namun mereka juga saling menyesuaikan satu dengan yang lain (Gorg and Hirsch 1998: 592-3). Dari jabaran diatas, mungkin bisa muncul pemikiran bahwa keterkaitan power negara dan pasar dapat menjadikan aktivisme 
transnasional menjadi tidak mungkin. Namun, elemen struktur power tetap memberi ruang untuk adanya resistensi.

Hal Ini berhubungan dengan konsep peluang politik yang dielaborasikan oleh Mc Adam (1996) dan Tarrow (1998). Konsep ini merupakan dialektikal alami bahwa aktivisme transnasional disatu sisi, dibentuk oleh struktur peluang politik dalam kerangka politik formal, namun disisi lain, aktivis transnasional juga berusaha untuk menciptakan struktur peluang politik yang baru. Ada bukti yang bisa disajikan bahwa institusi-institusi internasional memfasilitasi peluang politik bagi aktivisme transnasional. Sebagamana yang dipaparkan oleh keck, eksistensi dari regim pemerintah transnasional memberi peluang politik bagi aktor-aktor seperti negara dan gerakan sosial. Aktor-aktor yang secara relative tidak memiliki power dalam komunitasnya bisa menjadi diperhitungkan ketika dikenal oleh regim pemerintah. semakin terbuka sebuah regim pemerintah transnasional, maka akan semakin mudah bagi para aktivis untuk mendapatkan pengaruh.

Memperluas lingkup aktivisme internasional adalah sesuatu yang penting. Sebagai contoh, kelompok aktivis yang mampu menembus Washington dan Jenewa memiliki peluang yang lebih besar untuk mempengaruhi Bank Dunia, IMF dan WTO (O'Brien et al. 2000: 224). Kondisi ini, membuat NGOs-NGOs Asia menjadi lebih bergantung pada jaringan transnasional agar mendapatkan kesempatan untuk mempengaruhi kebijakan global. Konferensi-konferensi yang diselenggarakan oleh PBB merupakan agenda penting bagi aktivisme transnasional (Meyer and Pruegl 1999), meskipun konferensi-konferensi pada pada tahun 1990-an sepertinya tidak mungkin terulang. Banyak aktivis transnasional yang skeptis dengan PBB, karena berasumsi bahwa organisasi ini memiliki agenda untuk memantapkan bendera neoliberal.

\section{Diskursus dan Metode Komunikasi Power}

Dari perspektif konvensional power dapat disimpulkan bahwa secara keseluruhan pengaruh aktor transnasional relatif lemah (Khagram et al. 2002a: 11). Minimnya kemampuan power konvensional seperti kekuatan militer dan sumber daya ekonomi (meskpin beberapa INGOs dan NGOS cukup dibiayai), aktivis transnasional harus menyadari beragam bentuk power yang ada. Manfaat terbesar dari jaringan advocacy transnasional (TANs) jika dibandingkan dengan TNCs tidak perlu dibandingkan satu sama lain (Appadurai 2000: 17); namun issu kompetisi untuk mendapatkan pendaan dan mempertahankan minat publik secara keseluruhan masih terus membayangi antara TANs dan TNC. Aktivis gerakan sosial dan advokasi transnasional seringkali dilihat sebagai "soft power" atau komunikatif power" (Sikkink 2002: 303-6).

Yang penting disini adalah penggunaan strategi informasi dan persuasifnya dan membingkai isu dengan menerapkan moral. Florini (2000a: 214) mengungkapkan bahwa level bawah dari jaringan power transnasional hanya dapat bertahan sepanjang mereka mampu mempertahankan kredibiltasnya. Konsep "soft power", bisa menjadi salah pemahaman terkait dengan power dalam aktivisme transnasional dan sering diabaikan oleh jaringan aktivis. Teori-teori dan gerakan sosial menjadi lebih bermanfaat ketika diinspirasi oleh penelitian terkait studi-studi budaya (Escobar and Alvarez 1992; Alvarez, Dagnino and Escobar 1998; Guidry, 
Kennedy and Zald 2000b). Power dipandang sebagai konsep yang beragam dan potensial mendapat perlawanan. Perlu untuk mengawali konsep ini dengan mengadakan diskursus. "sebuah diskursus" yang dimulai dari serangkaian asumsi dan kapabilitas yang memungkinkan untuk mendapatkan informasi yang lengkap secara keseluruhan (Dryzek 1999: 34).

Menurut Dryzek (1999: 35), memungkinkan untuk menganalisa power dibanding menolak pembahasannya. Jika kita memahami aturan/kebijakan formal sebagai "perangkat keras institusional" diskursus-diskursus yang dilakukan dapat digambarkan sebagai "perangkat lunak institusional". "perangkat keras institusional" tidak cukup berkembang dalam sistem internasional, sehingga "perangkat lunak institusional" menjadi lebih penting dan cenderung kurang resisten terhadap demokrasi dibanding "perangkat keras insitusional” (Dryzek 1999: 35). Lebih lanjut, analisa diskursus paparan power nyata dari gerakan sipil transnasional terletak pada power komunikatif (Drtzek 1999: 45).

Sebagaimana yang dikembangkan oleh Foucault, power tidak hanya bersifat dominan, namun juga harus menyentuh semua aktivitas sosial (Sharp et al. 2000: 11). Yang ditekankan dalam diskursus ini adalah bahwa ragam persoalan dapat dibuat oleh manusia, membantu mereka untuk tetap bertahan dalam dunia yang mereka tinggali (Dryzek, 1999: 34). Dalam tulisan ini, diskursus pendekatan analitik yang utama diungkapkan oleh Lin, namun juga dijabarkan oleh Lindquist dan Keck. Sharp et al. And Dryzek memfokuskan adanya kemungkinan diskursus mengenai meningkatkan power dan mempertahankan fungsinya, Dryzek juga membuka diskursus dengan adanya ruang yang kondusif bagi demokrasi. Aktivisme transnasional dapat berubah dalam perdebatan-perdebatan diskursus tersebut. Politik konvensional yang minimu tetap diperlukan (uang, pribadi, akses ke media, kredibilitas), namun yang paling penting adalah kepekaan terhadap pentingnya memahami realita diskursus yang ada (Dryzek 1999: 44-45). Dengan menempatkan insitusi global/ pemerintah transnasional melalui "diskursus" para aktivis mendaptkan power dan pengaruh. Hal ini juga memungkinkan seperti apa yang diungkapkan oleh Sikkink (2000: 302) bahwa aktivisme transnasional berkontribusi terhadap "restrukturisasi dunia politik" melalui pembenahan struktur norma dari pemerintahan global.

Perspektif mengenai power sebagai serangkaian perubahan yang tidak secara eksklusif ditujukan pada orang-orang tertentu, institusi atau gerakan (Sharp et al. 2000: 20). Power dapat memiliki makna positif dan negatif, represif dan progresif, menghambat dan memfasilitasi (Sharp et.al.2000: 2). Namun, perspektif ini harusnya tidak menggiring pandangan yang terlalu optimistik terhadap perkembangan dan perubahan yang potensial dalam aktivisme transnasional. Masyarakat transnasional relatif mengalami sedikit hambatan dalam berkomunikasi, dan juga hambatan hirarki (Dryzek 1999: 46). Tidak ada emansipasi yang terlalu signifikan mengenai komunikasi dan informasi. Studi-studi mengenai masyarakat global memiliki kecenderungan untuk menyederhanakan hambatan tersebut melalui merubah informasi menjadi pengetahuan (Comor 2001). Fokus pada diskursus atau komunikatif power, menurut pemikiran penulis tidak hanya berkonsentrasi pada pemahaman komprehensif mengenai konteks power dari aktivisme transnasional. 
Namun juga harus dikombinasi dengan analisa lebih mendalam mengenai struktur power sebagaimana yang sudah disebutkan diatas.

Kita harusnya tidak melupakan bahwa power negara sangat signifikan dalam membentuk diskursus, sebagaimana kasus diskurus global mengenai hak asasi manusia, karena power negara-negara Barat, "hak asasi manusia" dipahami secara prinsip sebagai kebebasan liberal, bukan hak kollektif (Grugel, p.31).

\section{Simpulan}

Memahami konteks hubungan power eksternal terhadap jaringan aktivis transnasional dan power aktivis itu sendiri, tidaklah cukup. Perlu untuk menganalisa struktur power dengan jaringan. Aktivisme transnasional sama halnya dengan interaksi manusia, berhubungan erat dengan etnik, kelas dan perbedaan jender. Asimetri dan ketidaksetaraan power jaringan aktivis transnasional tidak hanya didasarkan pada perbedaan Utara-Selatan, meskipun ini sering menjadi persoalan utama. Struktur dari donor internasional terhadap gerakan kelompok masyarakat sipil cenderung memperkuat keberadaan kesenjangan ini. Pemikiran konvensional mengenai power memberi penjelasan yang bermanfaat mengenai fungsi dari aktivisme transnasional. Untuk mengetahui bagaimana dominasi power dan resistensi berinteraksi dalam jaringan aktivis transnasional, perlu memahamai analisa ini. Studi-studi terdahulu, cenderung membincangkan oposisi power antara negara dan masyarakat sipil. Studi-studi mikro dari power dan jaringan aktivis transnasional menunjukkan sesuatu yang lebih kompleks dimana power beroperasi melalui jaringan aktivis dan bagaimana power mempengaruhinya. 


\section{Daftar Pustaka}

Alvarez, S.E., Dagnino, E. and Escobar, A. (eds) (1998) Cultures of Politics Politics of Cultures: Re-visioning Latin American Social Movements. Boulder: Westview Press.

Anderson, J. (2002) 'Questions of Democracy, Territoriality and Globalisation', in J. Anderson (ed.), Transnational Democracy - Political Spaces and Border Crossings, London: Routledge.

Anheier, H., Glasius, M. and Kaldor, M. (2001) 'Introducing Global Civil Society', in H. Anheier, M. Glasius and M. Kaldor (eds) Global Civil Society 2001, Oxford: Oxford University Press.

Appadurai, A. (2000) 'Grassroots Globalization and the Research Imagination', Public Culture 12(1): 1-19.

Aviel, J.F. (2000) 'Placing Human Rights and Environmental Issues on ASEAN's Agenda: The Role of Non-Governmental Organizations', Asian Journal of Political Science 8(2): 17-34.

Boli, J. and Thomas, G.M. (eds) (1999) Constructing World Culture. International Nongovernmental Organizations since 1875, Stanford: Stanford University Press.

Braman, S. and Sreberny-Mohammadi, A. (eds) (1996) Globalization, Communication and Transnational Civil Society, Cresskill, NJ: Hampton Press.

Brecher, J., Costello, T. and Smith, B. (2002) Globalization from Below. The Power of Solidarity, Cambridge, MA: South End Press.

Burawoy, M., George, S., Gille, Z., Gowen, T., Haney, L., Klawitter, M., Lopez, S.H., Riain, S. and Thayer, M. (2000) Global Ethnography: Forces, Connections, and Imaginations in a Postmodern World, Berkeley, CA: University of California Press.

Castells, M. (1996) The Rise of the Network Society, Cambridge, MA: Blackwell Publishers.

Chen, Jie (2001) 'Burgeoning Transnationalism of Taiwan's Social Movement NGOs', Journal of Contemporary China 10(29): 613-44.

Cohen, R. and Rai, S.M. (eds) (2000) Global Social Movements, London: Athlone Press. 
Colás, A. (2002) International Civil Society. Social Movements in World Politics, Cambridge: Polity Press.

Comor, E. (2001) 'The Role of Communication in Global Civil Society: Forces, Processes, Prospects', International Studies Quarterly 45: 389-408.

Cullen, H. and Morrow, K. (2001) 'International Civil Society in International Law: The Growth of NGO Participation', Non-State Actors and International Law 1: 7-39.

Delanty, G. (2000) Citizenship in a Global Age, Buckingham: Open University Press.

Dryzek, J. S. (1999) 'Transnational Democracy', Journal of Political Philosophy, 7(1): $30-51$.

Edwards, M. (2001) 'Introduction', in M. Edwards and J. Gaventa (eds) Global Citizen Action, London: Earthscan Publications.

Edwards, M. and Gaventa, J. (eds) (2001) Global Citizen Action, London: Earthscan Publications.

Escobar, A. and Alvarez, S.E. (eds) (1992) The Making of Social Movements in Latin America - Identity, Strategy, and Democracy, Boulder: Westview Press.

Florini, A. M. (2000a) 'Lessons Learned', in A. M. Florini (ed.) The Third Force. The Rise of 22 Nicola Piper and Anders Uhlin Transnational Civil Society, Tokyo: Japan Center for International Exchange and Washington, DC: Carnegie Endowment for International Peace.

Florini, A. M. (ed.) (2000b) The Third Force. The Rise of Transnational Civil Society, Tokyo: Japan Center for International Exchange and Washington, DC: Carnegie Endowment for International Peace.

Fortun, K. (2001) Advocacy after Bhopal. Environmentalism, Disaster, New Global Orders, Chicago and London: University of Chicago Press.

Freres, C. L. (1999) 'European Actors in Global Change. The Role of European Civil Societies in Democratization', in J. Grugel (ed.) Democracy Without Borders. Transnationalization and Conditionality in New Democracies, London and New York: Routledge.

Gaventa, J. (2001) 'Global Citizen Action: Lessons and Challenges', in M. Edwards and J. Gaventa (eds) Global Citizen Action, London: Earthscan Publications. 
Gills, B.K. (ed.) (2000) Globalization and the Politics of Resistance, Basingstoke: Macmillan.

Görg, C. and Hirsch, J. (1998). 'Is International Democracy Possible?', Review of International Political Economy 5(4): 585-615.

Grugel, J. (1999) 'Contextualizing Democratisation: The Changing Significance of Transnational Factors and Non-State Actors', in J. Grugel (ed.) Democracy Without Borders. Transnationalization and Conditionality in New Democracies, London and New York: Routledge.

Guidry, J. A., Kennedy, M.D. and Zald, M.N. (2000a) 'Globalizations and Social Movements', in J.A. Guidry, M.D. Kennedy and M.N. Zald (eds) Globalizations and Social Movements. Culture, Power, and the Transnational Public Sphere, Ann Arbor: University of Michigan Press.

Guidry, J. A., Kennedy, M.D. and Zald, M.N. (eds) (2000b) Globalizations and Social Movements. Culture, Power, and the Transnational Public Sphere, Ann Arbor: University of Michigan Press.

Gurowitz, A. (2000) 'Migrant Rights and Activism in Malaysia: Opportunities and Constraints', Journal of Asian Studies 59(4): 863-88.

Hamel, P., Lustiger-Thaler, H., Nederveen Pieterse, J. and Roseneil, S. (eds) (2001) Globalization and Social Movements, Houndmills, Basingstoke: Palgrave.

Held, D. (1995) Democracy and the Global Order. From the Modern State to Cosmopolitan Governance, Cambridge: Polity Press.

Held, D., McGrew, A., Goldblatt, D. and Perraton, J. (1999) Global Transformations. Politics, Economics and Culture, Oxford: Polity Press.

Higgott, R.A., Underhill, G.R.D. and Bieler, A. (eds) (2000) Non-State Actors and Authority in the Global System, London and New York: Routledge.

Hulme, D. and Edwards, M. (eds) (1997) NGOs, States and Donors. Too Close for Comfort?, Basingstoke and London: Macmillan (in association with Save the Children Fund).

Jordan, L. and van Tuijl, P. (2000) 'Political Responsibility in Transnational NGO Advocacy', World Development 28(1)2: 2051-65.

Kaldor, M. (1999) 'Transnational Civil Society', in T. Dunne and N.J. Wheeler (eds) Human Rights in Global Politics, Cambridge: Cambridge University Press. New perspectives on transnational activism 23 
Keck, M.E. and Sikkink, K. (1998) Activists Beyond Borders. Advocacy Networks in International Politics, Ithaca and London: Cornell University Press.

Khagram, S., Riker, J.V. and Sikkink, K. (2002a) 'From Santiago to Seattle: Transnational Advocacy Groups Restructuring World Politics', in S. Khagram, J.V. Riker and K. Sikkink (eds) Restructuring World Politics. Transnational Social Movements, Networks, and Norms, Minneapolis: University of Minnesota Press.

Khagram, S., Riker, J.V. and. Sikkink, K. (eds) (2002b) Restructuring World Politics: Transnational Social Movements, Networks, and Norms, Minneapolis: University of Minnesota Press.

Kumar, C. (2000) 'Transnational Networks and Campaigns for Democracy', in A. M. Florini (ed.) The Third Force. The Rise of Transnational Civil Society, Tokyo: Japan Center for International Exchange and Washington, DC: Carnegie Endowment for International

Peace.

Lukes, S. (1986) 'Introduction', in S. Lukes (ed.) Power, New York: New York University Press.

McAdam, D, (1996) 'Conceptual Origins, Current Problems, Future Directions', in D. McAdam, J.D. McCarthy and M.N. Zald (eds) Comparative Perspectives on Social Movements. Political Opportunities, Mobilizing Structures, and Cultural Framings, Cambridge: Cambridge University Press.

McGrew, A. (1997) 'Globalization and Territorial Democracy: An Introduction', in A. McGrew (ed.) The Transformation of Democracy? Globalization and Territorial Democracy, Cambridge: Polity Press; Milton Keynes: Open University.

Markoff, J. (1996) Waves of Democracy. Social Movements and Political Change, Thousand Oaks, CA: Pine Forge Press.

Massey, D. (2000) 'Entanglements of Power', in J. P. Sharp, P. Routledge, C. Philo and R. Paddison (eds) Entanglements of Power. Geographies of Domination/Resistance, London and New York: Routledge.

Meyer, M.K. and Pruegl, E. (eds) (1999) Gender Politics in Global Governance, New York: Rowman and Littlefield.

Mittelman, J. H. (1999) 'Resisting Globalisation: Environmental Politics in Eastern Asia', in K. Olds, P. Dicken, P. F. Kelly, L. Kong and H. W. Yeung. (eds) Globalization and the Asia-

Pacific, London: Routledge. 
Nelson, P. J. (2002) 'Agendas, Accountability, and Legitimacy among Transnational Networks Lobbying the World Bank', in S. Khagram, J. V. Riker and K. Sikkink (eds) Restructuring World Politics. Transnational Social Movements, Networks, and Norms, Minneapolis: University of Minnesota Press.

O'Brien, R., Williams, M., Goetz, A.M. and Scholte, J.A. (2000) Contesting Global Governance - Multilateral Economic Institutions and Global Social Movements, Cambridge: Cambridge University Press.

Piper, N. and Uhlin, A. (2002) 'Transnational Advocacy Networks, Female Labour Migration and Trafficking in East and Southeast Asia. A Gendered Analysis of Opportunities and Obstacles', Asian and Pacific Migration Journal 11(2): 171-95.

Della Porta, D., Kriesi. H. and Rucht, D. (eds) (1999) Social Movements in a Globalizing World, London: Macmillan.

Princen, T. and Finger, M. (eds) (1994) Environmental NGOs in World Politics. Linking the Local and the Global, London and New York: Routledge.

Riles, A. (2000) The Network Inside Out, Ann Arbor: University of Michigan Press.

Risse, T., Ropp, S.C. and Sikkink, K. (eds) (1999) The Power of Human Rights. International Norms and Domestic Change, Cambridge: Cambridge University Press.

Risse-Kappen, T. (ed.) (1995) Bringing Transnational Relations Back In. Non-State Actors, Domestic Structures and International Institutions, Cambridge: Cambridge University Press.

Rucht, D. (1999) 'The Transnationalization of Social Movements: Trends, Causes, Problems', in D. della Porta, H. Kriesi and D. Rucht (eds), Social Movements in a Globalizing World, London: Macmillan, pp. 206-22.

Scholte, J.A. (1999) 'Global Civil Society: Changing the World?', University of Warwick, Coventry: Centre for the Study of Globalization and Regionalisation, Working Paper No. 31/99.

Sharp, J.P., Routledge, P., Philo, C. and Paddison, R. (2000) 'Entanglements of Power. Geographies of Domination/Resistance', in J. P. Sharp, P. Routledge, C. Philo and R.

Paddison (eds) Entanglements of Power. Geographies of Domination/Resistance, London and New York: Routledge. 
Sikkink, K. (2002) 'Restructuring World Politics: The Limits and Asymmetries of Soft Power', in S. Khagram, J. V. Riker and K. Sikkink (eds) Restructuring World Politics. Transnational Social Movements, Networks, and Norms, Minneapolis: University of Minnesota Press.

Smith, J. (2000) 'Social Movements, International Institutions and Local Empowerment', in K. Stiles (ed.) Global Institutions and Local Empowerment. Competing Theoretical Perspectives, Houndmills, Basingstoke: Macmillan and New York: St Martin's Press.

(2001) 'Globalizing Resistance: The Battle of Seattle and the Future of Social Movements', Mobilization 6(1): 1-19.

Smith, J. and Johnston, H. (eds) (2002) Globalization and Resistance: Transnational Dimensions of Social Movements, Lanham, MD: Rowman and Littlefield.

Smith, J., Chatfield, C. and Pagnucco, R. (eds) (1997) Transnational Social Movements and Global Politics. Solidarity Beyond the State, New York: Syracuse University Press.

Smith, M.P. and Guarnizo, L.E. (eds) (1998) Transnationalism from Below, New Brunswick and London: Transaction Publishers.

Tarrow, S. (1998) Power in Movement. Social Movements and Contentious Politics, 2nd edn, Cambridge: Cambridge University Press.

-(2001) 'Transnational Politics: Contention and Institutions in International Politics',Annual Review of Political Science 4: 1-20.

--(2002) 'The New Transnational Contention: Organizations, Coalitions, Mechanisms', paper presented at the APSA Annual Meeting, Boston, 31 August-1 September 2002.

Uhlin, A. (2001) 'The Transnational Dimension of Civil Society. Migration and Independence Movements in Southeast Asia', in B. Beckman, E. Hansson and A. Sjögren (eds) Civil Society and Authoritarianism in the Third World, Stockholm: PODSU/Stockholm University.

-(2002) 'Globalization, Democratization and Civil Society in Southeast Asia. Observations from Malaysia and Thailand', in C. Kinnvall and K. Jönsson (eds) Globalization and Democratization in Asia, London: Routledge.

-(2003) 'Regionalism from Below. Transnational Civil Society Links in Southeast Asia', in E. Palmujoki (ed.) Southeast Asian Regionalism from Above and from Below (forthcoming). 
Uvin, P. (2000) 'From Local Organizations to Global Governance: The Role of NGOs in International Relations', in K. Stiles (ed.) Global Institutions and Local Empowerment. Competing Theoretical Perspectives, Houndmills, Basingstoke: Macmillan and New York: St Martin's Press.

Warkentin, C. (2001) Reshaping World Politics. NGOs, the Internet, and Global Civil Society, Lanham, MD: Rowman and Littlefield.

Waterman, P. (2001) Globalisation, Social Movements and the New Internationalism, London: Continuum. 